\title{
Not quite white (enough): Intersecting Ethnic and Gendered identities in Looking for Alibrandi
}

\author{
Kathryn McInally
}

That Melina Marchetta's young adult novel Looking for Alibrandi (1992) remains one of the highest selling Australian Young Adult novels suggests the ease with which migrant identities are accepted and even celebrated in contemporary Australian culture. Teenage girls from a broad cross-section of Australian society enjoy identifying with Josie, the Italian-Australian protagonist, particularly her sense of (stereotypically adolescent) self-doubt which precedes her movement toward a more mature self-worth and world view achieved by embracing her cultural heritage. However, while such a widely celebrated novel seems to indicate the success of multicultural policy in Australia, the narrative's politically correct gloss disguises some profoundly assimilationist agendas. Thus, the impact of the book's representation of Josie's Italian identity continues to be significant to readers from many migrant backgrounds, especially when it comes from the apparently authoritative pen of a migrant writer. The ease with which Josie's story is enjoyed indicates not only that the assimilationist model for cultural acceptance is one readily embraced by the Australian readership, but equally that Josie's specifically gendered quest for a maturity that erases multicultural identity in all but its boutique (Fish, 1997) or overt manifestations, is one that is underpinned by an overwhelmingly monocultural ideology; that of acceptability attained through paternal sanction that transcends cultural heritage, to value aspirations for 'whiteness'.

This analysis of the novel assesses the intersections between raced and gendered identity, treating identity-formation as a function of biological, cultural and ideological codifications that cannot be readily disentangled. More specifically, I examine how these aspects of the protagonist's identity are reconciled through Josie's aspirations for, and eventual acquisition of a version of cultural capital that is accessible only through her relationship with men; a relationship, I will argue, that is framed through masculine domination, and which, as Bourdieu (2001) asserts, requires a feminine complicitness that the novel is all too ready to grant. While presented via an acceptance of 'Italian-Australian' hybridity, or multicultural positioning, then, Josie's desire for economic, social and symbolic capital is one that requires she move away from her Italianness, to a position that is markedly more hegemonic. Ghassan Hage's argument, that whiteness is in itself a form of cultural capital able to be acquired (Hage, 1998), informs my reading of Looking for Alibrandi. The novel can be analysed in ways consonant with Hage's assertion that "whiteness and Australianess can be accumulated (up to a certain point) and people can be said to be more or less White and Australian. How white they can be depends on the social attributes they possess" (Hage, 1998, p.20). This perspective on accumulating whiteness enables a reading of how the feminine may only access such capital through acquiescing to what the novel constructs as a 'universal' patriarchy. Looking for Alibrandi embodies this intersection of identity politics in ways that suggest that rethinking multiculturalism (and whiteness) might also mean rethinking gender. I will argue that the novel's overt celebration of a multiculturalist agenda can be set against the way social capital accrues to an adolescent female who becomes a 'daddy's girl'.

Of course the meanings attributed to 'whiteness' are many and contestable. What I look at here, specifically through Josie's gendered quest for acceptance, is not a whiteness defined by skin, particularly because by the '90's in Australia, the socio-historical period that is the setting of Josie's story, European migrants were coded 'white(r)' against the newer 'otherness' of migration from non-European countries, (what Hage terms TWLMs; third world looking migrants). Rather, whiteness is embodied in a desire for whiteness, an aspirational positioning involving a slippage between, and conflation of, 'whiteness' and cultural capital. My use of 'whiteness', then, is premised on an acceptance of Hage's contention that whiteness cannot be conflated with Anglo or Anglo-Celtic, because 'Anglo could not account for the many non-Anglos who relate to and define themselves through the "White nation" fantasy' (1998, p.19). In my gendered reading of the text, however, it is masculinity that is the exemplar of whiteness, even though Italianness is depicted as marginal to white Australian culture at the beginning of the novel. Femininity is thus 'othered' through ethnicity, and the novel proposes that this form of otherness can and should be transformed through an acceptance of both whiteness and patriarchy.

I first consider Josie's cultural position as AustralianItalian through an analysis of her relationship to her 
father, whose presence allows her an identity that while seemingly multicultural, is nonetheless underpinned by a conservative assimilationist agenda. I then attend to Josie's paternal/patriarchal heritage and how this reinstates and reifies her desire for cultural whiteness. Finally, I analyse the structure of the novel by looking at the gendered power relationships it promotes through Josie's boyfriend, Jacob Coote, whose role in the novel is to enforce the idea that there is only one position for a 'good migrant girl'; a position not informed by her culture as the book superficially argues, but by a dominant masculine voice, recognizable as 'white'. Jacob's role in the novel is also significant in undermining the power of class locations in this sociocultural analysis of the text. While Josie's manifold anxieties around her position in Australian culture include her sense of belonging to a lower class as a scholarship girl in an expensive private school, the two boys she desires split the class difference; John Barton is an upper-class boy who suffers from the pressure to maintain his status, a pressure that ends in his suicide; and Jacob is a lowerclass boy who promises to become successful at the novel's close. This class dynamic in the text (also figured through masculine characters functioning as emblems of power) demonstrates that the social capital that is so desirable to Josie works to support the superiority of masculinity; superiority that is dependent on the masculine characters' success in accumulating whiteness irrespective of class.

The story follows three generations of women in the Alibrandi family: Josie, the adolescent protagonist, her mother Christina and her mother's mother Nonna. Josie is fatherless at the beginning of the narrative, and her grandfather is dead. However in this apparently matriarchal family the power vacuum is filled by installing fathers who culturally and sexually assimilate Josie into a normative social position. In terms of her racialisation, the key element of the plot involves her discovery that her long-despised Italian grandfather is not really her grandfather at all. Her grandmother's dark secret is that she had a sexual liaison with a man who is the very emblem of the white Australian male and the tryst between this man and her grandmother resulted in the birth of Josie's mother. Josie thus discovers that she has white Australian (grand) paternity. While this information is in some ways relegated to the background of the plot and Josie overtly identities with her Italian culture and community through reconciliation with her (second generation) Italian father, this biologically proven whiteness is nonetheless an embedded indicator of her possibilities for merging seamlessly into white Australian culture.

The kinds of cultural diversity that the novel promotes, then, are fraught with contradictions: through its construction of a naturalised patriarchy it promotes an essentialist representation whereby, in all characters except her nonbiological grandfather, Nonno, men are not only seen as deserving of power and authority, but enable Josie to attain the things that she desires. The novel's overt theme of Josie's maturation has her grow from articulating her desire for money, popularity and prestige to a position where, ostensibly, her desires are more wholesome: "But now all I want to be is an insignificant Italian in a normal Italian family where there is a father and a mother and grandparents who have all stayed married to one person" (p.219). At this point, just prior to the closure of the book, Josie still aspires to be 'normal' but does not yet fully consider herself in these terms. She achieves this 'normality' by the conclusion of the novel, when the slippage between 'normality' and 'whiteness' is masked by 'family values' that see Josie doubly assimilate: assimilate into 'Australian' lifestyle that is 'liberatory' because she is liberated from the 'problems' of being of Italian descent, and assimilate as a girl, into patriarchally sanctioned ways of embodying gender and enacting sexuality. While the text ostensibly promotes acceptance of difference, it works instead to reinforce the idea that instead of maintaining relationships with the women in her family, developing friendships with other women or understanding her own identity, it is crucial for Josie to be a 'daddy's girl' in a highly conservative and disempowering way.

\section{All about Daddy}

As with much Young Adult fiction, Looking for Alibrandi is structured through a maturational sequence that displaces her mother (who has brought Josie up alone for seventeen years) with self-knowledge gained from her new relationship with her father. This is first established through the attention the text pays to the opportunities that her father, Michael, can provide for her; opportunities unavailable to 
her from her mother. Prior to Michael's appearance in her life, Josie complains that she can never 'compete' with someone whose father is successful (p.43). Moreover, rather than living with her mother and attending school as a scholarship girl, she 'would rather be the daughter of a labourer' (p.6). These comments reflect Josie's acceptance that power and success, the acclaimed capital in the text, are available to her only through her father. More than this, they imply that the father, indeed any father, is the indicator of quality of life par excellence regardless of the class location of his profession.

Michael's own Italianness is established early in the text in order to highlight Josie's problematic and ambivalent feelings about her Italian heritage, which, at the level of plot, she must transcend. And yet Michael's Italianness is overshadowed by his successful position as a barrister; he has a mastery over Australian institutions (in this case legal) that reinforces white dominance. This is established when Josie finds herself in a situation at school where it is only Michael who can assist her, and this is the basis from which they build a father/daughter relationship. Josie is called to the principal's office after hitting another girl for calling her a 'wog'. Michael's response to the incident is that rather than react in such an infantile manner, Josie must take pride in her Italianness: 'You are a wog, Josie. Does it offend you to be one?' (p.89). And yet there is little 'woggyness' in Michael; he may not be Anglo-Celtic, but his accumulated whiteness is evident in the way he positions himself as the opposite to a 'wog'. In one of the few references to Michael's Italianness he tells Josie that his biggest problem as an adolescent was avoiding marriage to an Italian girl, Maria Lucianni: 'If I'd married Maria, Josie, I would be sleeping on purple satin sheets' (p.159), rather than, perhaps, 'fly[ing] business-class Australian' (p.156). While Jon Stratton, in his compelling analysis of music in multicultural Australian film asserts that Michael has experienced the same kinds of symbolic violence and has learned to rise above it, and further that he has accepted his own Italian heritage, he also recognizes 'Andretti's assimilatory shift from his Italian heritage' (2005, p.14). Due to the fact that Michael is the most successful character in the novel, this assimilation is presented as a positive position.
In the same episode, Michael deals with Ron Bishop, the father of Carly Bishop, whose nose Josie breaks in a heated argument. While Ron is a famous television personality this is shown to be less valuable as cultural capital than Michael's position as 'an intellectual. He watches SBS or the ABC' (p.89). The text seemingly flips dominant power relationships and ascribes more cultural capital to Michael than the very white Ron. However cultural capital here cannot be measured in terms of ethnicity because, as Hage points out, there is no essence to whiteness: 'Whiteness is an aspiration' (1998, p.20). This case is effectively a battle between fathers; fathers who accumulate social capital which allows them agency and views that can be articulated legally and legitimately, what Hage terms 'governmental belonging' to the nation (1998, p.46). This power to speak and act in ways that make a difference - in ways, too, that are inscribed as whiteness - are shown to be embodied in Michael. Through Michael's access to the Australian legal system, and through his triumph over Ron Bishop he further accumulates whiteness as cultural capital. Michael's Italianness in this novel, then, has been subsumed into whiteness, a category that Jon Stratton argues is one that has been 'abstracted into a general moral system...monomorality, which by implication is white' (1999, p.180). At the same time, the power of patriarchy as part of a monomoral culture that privileges whiteness is naturalised to the point where Josie accepts that the accumulation of whiteness entails the acceptance of the prime and pivotal role of fathers in a teenage girls' normative development and maturation. Josie's own accumulative whiteness and Australianness is also evidenced in this episode, when she points out correct Australian legal terms: 'I almost snickered aloud. I would have liked to explain [to Ron Bishop] that solicitors weren't called "lawyers" in this country' (p.83).

Michael encourages his daughter's desire for the trappings of success, the cultural, economic and symbolic capital that is displaced onto the ideology of Australia as the 'lucky country', for those, anyway, who take on and promote 'Australian values'. Michael personifies these values, summed up by John Howard, as 'a fair go for all'. In the context of contemporary Australian politics, this apparent egalitarianism 'fair go', however, is mediated through 
what Howard previously stated as what he regards as the necessity for 'balance' when dealing with intercultural relations and legislation regarding multiculturalism. In his address to the National Press Club in 2006, Howard explained that 'our goal must be to strive for a balance in questions of national identity and cultural diversity. ...We've drawn back from being too obsessed with diversity to a point where Australians are now better able to appreciate the enduring values of the national character that we proudly celebrate and preserve". Josie's own maturation, dependent on her relationship with Michael, show her overcoming her own obsession (as Howard might describe it) with her Italianness, to a point where, while she declares herself an 'Australian with Italian blood flowing rapidly through [her] veins' (p.259), she tips the 'balance' and looks to a more universal (white male) character of goodness, which subsumes cultural difference under the rubric of global compassion:

\section{I'll believe in my world. A world where an Irishman told us to feed the poor and we fed the poor. Where musicians asked us not to 'Sing Sun City' and we supported them against the segregation between blacks and whites. A world where Sting asked if the Russians loved their children too...}

$$
\text { (p.260) }
$$

This newly acquired politicized maturity detailed in the last pages of the text, however, relies on a naturalisation of paternalism. Howard's paternalistic style of politics (evidenced last year in his decision to take control of Aboriginal land and parenting practices 'for their own good'), is mirrored by Michael's intrusion in Josie's life, which nonetheless informs her sense of self. As Josie's friend, Lee, notes, 'Without being there he's [her father] still managed to be the greatest influence on your life' (p.144). The centrality of paternal influence and the status of this presence ('the greatest influence') equates with Josie's success and acquisition of cultural capital, both in her resolution with her culture, family, religion, race and gender, and, according to the ideologies presented in the text, her own personal growth. The paternalistic intrusion that underpins the excuse for further invasion into lives that do not fit the white/normal construction, then, reinforces the hierarchy where patriarchal whiteness retains its authority in both ideological and practical terms.

Part of Josie's personal growth and maturity is coded in her desire to get a part-time job. But little economic, social or symbolic capital accrues from working at McDonald's, her first experience of the workplace. Rather than see Josie working at McDonalds, Michael offers Josie a job at his law firm. Her new job description entails photocopying and making Michael coffee (p.156). This startling opportunity enables Josie to further establish a relationship with her father, so that she is able to embrace his authority as represented by his position both in the law, as her employer whose whims she must serve, and in his paternal presence; arguably the same thing. Josie's maturation entails her awareness of the shift in her circumstances following her father's entry into her life. The novel credits Michael's presence with enabling her a different, more mature world view. Shifting from the initial dyadic relationship with her mother, Josie is increasingly conscious (and appreciative) of the centrality of the father, and how the process of her maturation is a consequence of this: 'I'm still shocked by how fast things are going between us. Six months ago I hadn't met my father... [now] we've developed a great relationship' (p.156). This relationship is 'great' for Josie because it provides her the opportunity to accumulate not only economic and social capital, but symbolic capital such as prestige and reputation. From a position where Josie says 'I hate the word respect' (p.40) prior to meeting her father (thus demonstrating a disregard for law and dominant culture), she takes on a more 'mature' attitude after establishing a relationship with him: '...there is a great respect' for Michael (p.156). Josie recognizes the power that devolves from official processes, and thus she acquiesces to Michael's wishes both by taking his name: 'I'd be so proud to be an Andretti ...Dad' (p.244), and through her agreement with her father that, like him, she will substitute her glasses for contact lenses; metaphorically, that she will view the world in the same way as he does, through a patriarchal lens (p.243).

\section{Good fathers, naturally}

Within this affirmation of traditional patriarchal structures that rely on the accumulation of 'whiteness' Alibrandi 
attends to what 'fatherhood' is, and should be, and designates it with a specific meaning. This reactionary narrative prioritizes 'natural' biological fathering, and constructs this as what is good, right and proper. However rather than the novel offering a negotiation of the way biology functions in constructions of race and ethnicity, biological fathering takes on a raced meaning because the Alibrandi family is very literally founded in whiteness through Josie's biological grandfather, Marcus Sandford. Things get confused, the text asserts, when cultural circumstances disrupt the natural 'order of things' where whiteness is privileged. This is proposed most clearly through the Italian character of Nonno, the abusive husband and father whom Josie has always believed to be her biological grandfather.

The character of Nonno Francesco may seem to offer an interrogation of dominant masculinity and patriarchy at its most violent. He is constructed entirely in negative terms as abuser, cheat and liar, yet he represents the law of patriarchy. This linkage appears to offer some critique of a patriarch social structure which oppresses women. However the text treats Nonno as an aberration in the context of ItalianAustralian cultural life by juxtaposing him with the 'true' head of the extended family, Zio Ricardo, whom everyone 'loves and adores' (p.217). Further, Nonno reinforces what 'real' masculinity means in this culture by his construction of what it is not, coded through his sexual infertility: Josie discovers her 'true' grandpaternity only when her Nonna Katia tells her that Nonno could not father children. Thus, Zio Ricardo, Michael, and the 'true' grandfather, Marcus Sandford reinforce and affirm a particular and specific representation of patriarchy in the masculine virility that allows them to produce offspring.

These characters embody the goodness attributed to patriarchy in the text, and more specifically to the whiteness that validates it, to the point where Josie's mother, Christina has positive character traits that directly reify the biological bond (to whiteness). Nonna says: 'I see [Marcus] every time I look at Christina. Do you ever wonder where her gentleness comes from, Josie? That serene feeling about her. She got that from her father' (p.225). This specific and designated (biological/natural) fatherhood has previously been identified by Josie in her rejection of any romantic relationship between her mother and a potential lover, Paul Presilio. Josie's anger and fear concerns the possibility of Paul stepping into a role as father through a sustained relationship with Christina. Josie notices that Paul has '...the look of a man who wanted to settle down' (p.97). Josie feels relief that the 'right' man is not Paul, and has never come along for Christina. This is because the 'right' man is only ever the one in Josie's dreams: Michael. Josie reminds Christina how the biological bond is of utmost importance: when Christina is angry with Josie, she says to her: '... I don't know what I did to deserve you.' Josie's reply refers back to her conception: 'I can tell you what you did with [Michael]' (p.99). Through Michael's intrusion Josie forgoes the exclusionary relationship she once enjoyed with her mother and comes to acknowledge the role of the 'real' father, Michael, a role that directs her toward feeling 'normal' within a white Australian context.

The abundance of 'good' (biological) fathers in this text collectively constructs a benevolent version of patriarchy. Since historically patriarchy has relied on a belief in biological fathering to reproduce itself (and contemporary society still retains laws to protect this) the text's attention to this same ideological structure works to assist patriarchy in its own reproduction in the most conservative mode. This 'real' patriarchy is validated through the whiteness embodied in Marcus Sandford and suggests that goodness and whiteness have an intrinsic link. The text specifies this in its description of Nonno: 'He never smiled. He was always standing straight and haughty. He was extremely tall for an Italian and very dark' (p.115, my italics). This description, while relatively self-evident in its conjunction lof darkness with negativity, becomes overt when juxtaposed with a description of Marcus Sandford, the 'spunk' according to Josie's assessment of his photograph: '[He] was of medium height with golden brown hair. He was smiling broadly, leaning against a shovel, with no shirt on' (p.115). This iconic image of a 'real Aussie' is valorized by Josie: 'This man [Marcus Sandford] exists more for me than Nonno Francesco did. I feel as if I know Marcus Sandford more' (p.199). Josie's (biological and emotional) link to Marcus Sandford and her eventual acceptance of her own Italian heritage is predicated on the knowledge of her own 
whiteness and is underpinned by her monomorality; her newly found respect for patriarchy.

The text's overt celebration of Josie's multicultural position, then, is already structured through the men in her history and in her present. This pattern continues in her relationship with her new boyfriend, Jacob Coote (whom only Michael is allowed to call Jake). Jacob is described in strikingly similar terms to Marcus Sandford; a 'spunk' who by consensus among all Josie's friends, is 'gorgeous', with his 'rolled up sleeves and tanned arms' (p.31). Like Marcus Sandford who established a relationship with Nonna when many Australians did not offer such tolerance and friendliness, Jacob is the 'epitome of individuality' (p.55). It is Jacob who reinforces the symbolic violence associated with Josie's sexuality, in that her decision not to have sex with him is predicated on fear and anxiety rather than, as the text superficially argues, agency and choice.

\section{Virginity anxiety and big boys' bikes}

The patriarchal ideology in Alibrandi is established through the novel's attention to sexuality, whereby Josie comes to 'know' herself through her relationship with Jacob Coote. The coincidence of her father's arrival in her life and the appearance of boys as desired and desiring partners is more significant for the novel's multicultural project than its Freudian banality might first suggest. Josie's first experience with Jacob is keenly intense for her, and occurs when Jacob offers Josie a lift home on his motorbike. Josie is extremely anxious about this new experience, feeling that not only is it dangerous but that her Italian family and the whole Italian community who, she feels, acts as a constant surveillance network reporting on her activities to Nonna, might discover her in the compromised position of physical(and metaphorically sexual) behavior of straddling a motorbike pressed closely to the male rider. In this way Josie's anxieties about the motorbike ride might be read metaphorically in that she substitutes emotions over the bike ride for her real anxiety about sex. This fear and anxiety regarding sexuality is preceded by other episodes in the novel; however the following passage clarifies the anxiety Josie feels over her first-time experience:
'It's the panel van, isn't it,' I groaned. 'Oh god, I know you'd be the type to have one of those. My reputation is ruined.'

'Wrong guess,' he said, stopping beside a motor bike and leaning on it...

'I am wearing a good velvet dress ... it'll probably be a family heirloom one day. How could you suggest I sit on that bike with my family heirloom on?'...

'Turn around while I get on. It's bad enough that the whole of George Street is going to get a glimpse of my undies.'

'You're denying me that honour?' he asked, wounded as he turned around....

'Let me check my bag for ID. I don't want to be named something as plain as Jane Doe in the hospital'

'You are one morbid chick' he groaned, stepping on the bike to start it.

I screamed. A long piercing scream...Ifelt strange being so exposed. I mean we were unprotected from all those weird people who walk around after midnight...My face burnt with embarrassment. Ijust felt as if the whole world was watching me...

It was only thirty seconds away from my street that I began to enjoy it...My eyes smarted form the wind and my skin felt tight, not to mention my throat hurting from all the screaming...I pulled up my dress again quickly, trying to get off before he turned around but when I stood up after adjusting it around my knees, I knew he had seen every movement....He was quiet as we walked down the street almost in his own world, and I wondered what boys like Jacob Coote thought about.

(p.59-61)

Josie's fear about preserving her 'family heirloom' is arguably a metaphorical desire to preserve her virginity, which is a form of cultural capital in patriarchy. The physicality of tight skin (the hymen) and smarting eyes (the fluids associated with female sexuality) indicate that her objections are overcome when she allows herself to be 'carried away' (on Jacob's bike). While Josie wants to deny Jacob 'the honour' of 'getting a glimpse of her undies' (genitals), as she does later in the novel, she is also 
compliant with Jacob's wishes, wanting to preserve her 'modesty' after exposing herself to him. The motorbike ride metaphorically represents how Josie perceives sexual intercourse, and is riddled with anxiety and conflicted feelings; fear and enjoyment, exposure and modesty. In the context of the narrative as a whole this anxiety arguably the way girls should feel about sexual activity. Yet Josie begins to enjoy this ride. This is when the 'thrill' of being in tandem with a white boy becomes more important to her than her embarrassment about the markers of her ethnicity: her velvet high-necked dress made by Nonna and the awareness of the cultural surveillance that insists she follow the rules of her Italian heritage. The 'freedom' afforded by whiteness allows escape from the restrictions of her heritage, but are, importantly, only afforded to her by way of the entirely masculine (white) Jacob.

The textual link between Josie's metaphoric experience and her anxieties regarding sexuality is made explicit when Josie engages in sexual activity with Jacob in his room: '...but then ... his hands went up between my thighs and I looked up to see a poster of a motorbike that said "Get something between your legs" on it.' At this point Josie halts foreplay and says 'No more, Jacob' (p.211). Josie's anxiety about her virginity ostensibly regards choice: '...I can only give it away once and I want to be sure when it happens, Jacob' (p.213), but retains a moral agenda regarding normative developmental maturity: 'One day someone will tell your daughter that she's only thirteen and everyone else is doing it' (p.213). This dialogue works to prioritise heterosexual genital sex based on the value of virginity and establishes this position as entirely natural. Josie's sexuality, then, is formed through an acceptance of, and desire for the whiteness that is embodied in Jacob, and also through a desire for the cultural capital that comes with patriarchy's most traditionally prized possession: virginity.

Josie's virginity anxiety and subsequent (mono)moral position informs a particularly passive picture of feminine sexuality. This is apparent in Josie's characterisation of her girlfriends, where sexual activity or virginity is associated with particular character traits. Josie's respected (white) friends, Anna and Lee, are, like herself, virgins, while Sara, the (Italian) character constructed in entirely negative terms, is sexually active. Josie describes Sara this way:
'Then there's Seraphina... She can look a person straight in the eye and lie her heart out. She can bitch about a person for three hours straight and then turn around and crawl to them... and she's the only one of us who's slept with a guy...' (p.19). Importantly, too, in terms of the novel's broader characterization of whiteness, Sara is 'the stereotype of a wog'(p.20). Thus, sexuality cannot be disentangled from the representation of Italianness in the novel, and the character of Sara is seen as less than attractive in the enactment of femininity. Sera is the "purple satin sheets' version of 'wog' that Michael despises and thus she reinforces that Josie's gendered and sexual identity needs to comply with ideals of patriarchy as well as whiteness.

Sara's 'promiscuity' is also mirrored in her physical characteristics: 'She has black roots and blonde hair teased from here to eternity. She's skinny, yet voluptuous and tends to dress in whatever the latest rock or pop star is wearing' (p19). Clearly, in this text, Sara is the antithesis to a role model, again reiterated in her comment on sex: '...I don't believe you should be a virgin when you get married... you should experiment...men do' (p.256). Rather than the text presenting different perspectives regarding sexuality, however, the context of the narrative puts Sara firmly in her (negative) place with Josie's reply: 'Yes, but only if you're in love with them' (p.256). The problem with Sara is that she does not understand Australian culture enough, nor accumulate whiteness in a patriarchally sanctioned way. Sara masquerades as white (the blonde tips), but still has her black roots, her Italianness. Indeed, unlike Josie, the boys Sara hangs out with are Italian-Australian, boys the reader is positioned to see as entirely distasteful with their 'woggy' habit of tearing around in their cars with their music blaring. In comparison, Jacob Coote's motorbike is 'tasteful', even though he later trades his motorbike for a car.

The overwhelming insistence that passive (hetero) sexuality must be played out by the girls further emphasises Josie's position as perpetuating the monomorality that underpins white dominance because the novel confuses this passive position with western ideas about romance and love. When Josie and Jacob eventually end their relationship, or rather when Jacob ends it, Josie sums up her feelings: 'I believe in my heart that one day I will be with Jacob Coote 
again' (p.260). Josie clearly aspires to reconcile with her blonde boyfriend, and anticipates a future that embraces a normative position for the feminine as passive and without agency. Josie reflects on the reasons why the relationship did not work out: 'I think that during the year Jacob got a bit more ambitious than he used to be and I became a bit less...but I'm not going to make that a problem or a hang-up' (p.260. emphasis mine). While this acquiescence to patriarchy is indeed not culturally specific, it is infused with Josie's desire for whiteness. As an ethnicised subject, Josie enables opportunities for Jacob, in that his growing ambition is seen in terms of upward mobility, while her own ambitions gradually diminish. This formulation of cross-cultural relations clearly perpetuates the kinds of boutique multiculturalism whereby the 'other' is accepted, or tolerated, only for the ways they can enrich the host culture (cuisine, dance, music festivals, for example), in the same way that Josie enriches Jacob's life.

When in the final stages of the story Josie is reflective and states that 'My emancipation didn't happen like I expected it to' (p.258), she refers to the lessons she learned growing up in the year chronicled in the novel. However what Josie is emancipated from are the problems associated with not feeling 'normal' at the beginning of the novel. These problems can be translated in terms of not having a father, not feeling part of, or accepted by dominant white culture and not experiencing herself as attractive to boys. The conclusion of the text sees Josie rewarded for her newfound maturity in dealing with these problems. She has a father who 'expects of me, not what I want, but what he feels that I want' (p.259) and a (white) Australian heritage. She accepts herself and thus feels accepted: 'I know where my place in life is' (p.258), and she has been desired by an ambitious (white) boy. Josie's emancipation, then, relies on an accumulation of whiteness throughout her story, but also on accepting a passive position that reifies the goodness of a naturalised patriarchy. Josie's 'mature' subjectivity in the novel's closure is attained through her assimilation into dominant monomorality; accepting the 'rightness' and 'whiteness' of male domination in the equality white and patriarchal Australia as her embraced homeland.

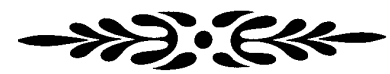

\section{REFERENCES}

Bourdieu, P. 2001, Masculine Domination, Polity Press, Cambridge. Trans Richard Nice.

Fish, S. 1997, 'Boutique Multiculturalism, or why liberals are incapable of thinking about hate speech', Critical Enquiry, vol.23, no.2, pp.378-395.

Hage, G. 1998, White Nation: fantasies of white supremacy in a multicultural society, Pluto Press, N.S.W.

P.M Howard's Australia Day Address to the National Press Club, January 25, 2006. http:// australianpolitics.com.news/2006/01/06-01/25_ howard.html

Marchetta, M. 1992 (2000), Looking for Alibrandi, Penguin, Ringwood, Australia

Stratton, J. 1999, 'Multiculturalism and the whitening machine, or how Australians become white', The Future of Australian Multiculturalism, Eds. Ghassan Hage and Rowanne Couch, Research Institute for Humanities and Social Sciences, University of Sydney, N.S.W., pp.163-188.

Stratton, J. 2005, 'Lost in music: popular music, multiculturalism and Australian film', http:// espace.lis.curtin.edu.au/archive/00001115/02/ LostinMusicRCredit\%5B2\%5D.pdf

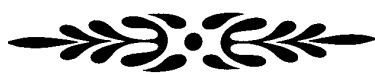

\section{BIOGRAPHICAL NOTE}

Kate McInally completed her $\mathrm{PhD}$ candidate at Deakin University where she teaches children's literature. She is currently a Research Fellow with Clare Bradford and Wenche Ommundsen in the ARC Discovery Project 'Building Cultural Citizenship: Multiculturalism and Children's Literature'. Her particular interests are contemporary Australian young adult fiction and queer theory. 